Original scientific paper

\title{
THE PATH TOWARDS ACHIEVING A LEAN SIX SIGMA COMPANY USING THE EXAMPLE OF THE SHINWON COMPANY IN SERBIA
}

UDC 658:005.5

\author{
Srđan Mladenović ${ }^{1}$, Peđa Milosavljević ${ }^{1}$, Nevena Milojević ${ }^{2}$, \\ Dragan Pavlović ${ }^{1}$, Milena Todorović ${ }^{1}$ \\ ${ }^{1}$ Faculty of Mechanical Engineering, University of Niš, Serbia \\ ${ }^{2}$ Shinwon doo Niš, Sales Department, Niš, Serbia
}

\begin{abstract}
In the last twenty years, many companies have realized that the demands of the global market, including more demanding and receptive customers, have set new standards for production flexibility. Gradual reduction of mass production, characteristic of a large number of companies, has opened space for the introduction of a new system which focuses exclusively on the customer. The customer-oriented system was created with the idea that process optimization would lead to the production of a relatively cheap product, delivered on time and with the best possible quality. Such a system is achieved by applying the Lean Six Sigma concept. The aim of this paper is to identify all of the defects that occur as losses and complicate the process of production in order to achieve the Lean Six Sigma level in the Shinwon Company. The original data from the Shinwon company were identified, collected and analyzed, using the methods and tools of the Lean Six Sigma concept (Process Mapping, 5S audit, Pareto diagram, Ishikawa diagram, Seven basic wastes and SPC analysis), in order to present the effectiveness of the quality management system and to evaluate the possibility of its continuous improvement.
\end{abstract}

Key Words: Lean, Six Sigma, Pareto Analysis, Ishikawa Diagram, Waste, Statistical Process Control

\section{INTRODUCTION}

Lean and Six Sigma methodologies were developed each on its own but globalization and competition as well as the constant need of companies for improvement have recently

Received March 03, 2016 / Accepted July 17, 2016

Corresponding author: Srđan Mladenović

Faculty of Mechanical Engineering, University of Niš, Aleksandra Medvedeva 14, Niš, Serbia

E-mail:maki@masfak.ni.ac.rs 
merged these two methodologies into one [1]. There are many companies today that have realized the necessity of applying the Lean Six Sigma methodology and they have profited from it [2]. Among them are: General Electric, Sony, Citibank, Whirlpool and many others.

Successful application of the methodology has been given in many papers so far, including not only implementation but also the positive results that the companies have achieved [3]. This combination of the Lean practices with the Six Sigma has gained huge popularity in recent years [4]. The Lean Six Sigma methodology has been used in a wide range of projects involving specific industrial problems [5-7]. Its application in SME is given in [8] relating to manufacturing and production companies, as well as in railway sector [9]. The original Lean Six Sigma method originated from automotive industry; therefore, its application and continuous implementation are directly bound to this sector, as can been seen in [10].

The Shinwon Company has also been caught by this global economic trend. The system of production fostered in this company must be continuously evaluated, improved and perfected. The goal of this paper is to identify all of the defects that occur as losses and complicate the process of production in this company, as well as the final proposal of improvements in order to move the entire organization towards a Lean Six Sigma organization [11]. Further in the paper, the data from the Shinwon Company are identified, collected and analyzed in order to present the effectiveness of the quality management system and to evaluate the possibility of its continuous improvement. Once they are collected, the data are analyzed using the methods of the Lean Six Sigma concepts (Process Mapping, 5S audit, Pareto diagram, Ishikawa diagram, seven basic wastes [12], and SPC analysis with the aim of improving business quality.

\section{PRODUCTION PROCESS IN THE SHINWON COMPANY}

In this paper we will particularly pay attention to the production process as one of the basic processes of implementation in the company.

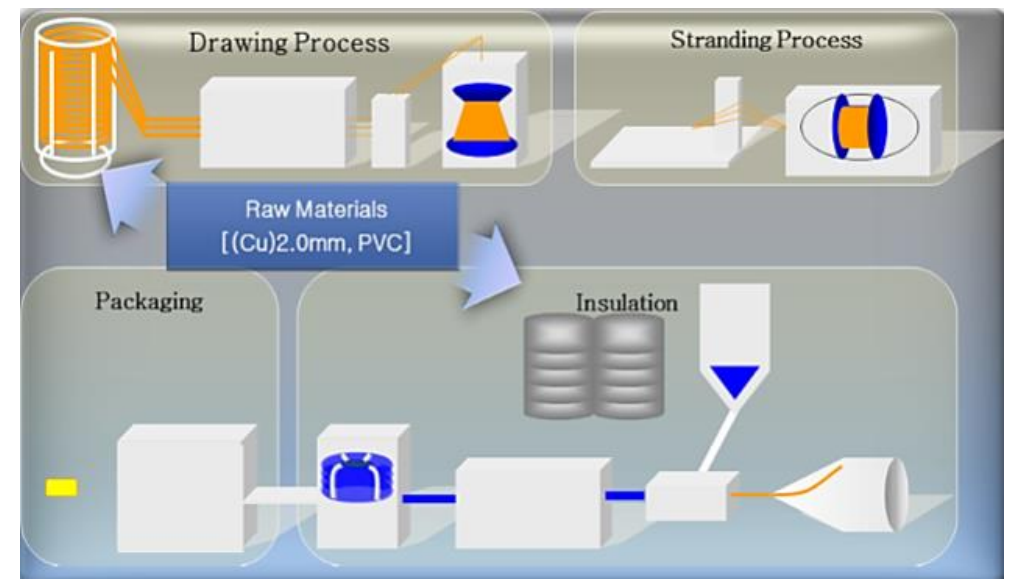

Fig. 1 Schematic view of the production process in the Shinwon Company 
The production process consists of 4 phases (Fig. 1):

- The process of drawing wire from $8 \mathrm{~mm}$ to $2 \mathrm{~mm}$;

- The process of drawing wire from $2 \mathrm{~mm}$ to smaller diameters;

- The process of stranding wires;

- The process of insulation.

\section{LIST OF 7 BASIC TYPES OF WASTE}

Based on the defined parameters through which the production process is monitored in the Shinwon Company, we can see that most of the waste is included in the following categories: breaks, additional time, loss during manufacturing, specialization and training. The only element that would add value to the product would be the category of the performance of production workers in the form of the amount of produced wire based on which the performance of each worker would be monitored, along with the performance of a team on the machine, the team leader and the entire production. Other elements comprise the so-called category of eligible or approved costs and that category increases the performance of workers but reduces productivity.

The additional time category includes all the additional time that the worker needs in the execution of work; it is not standardized but not due to the worker's fault. This group of eligible expenses includes the time required for additional cleaning of machines, change in the color of PVC, ink changes, changes in the wire size, etc.

Breaks include all delays due to malfunctions of machines.

Training includes the time that is recognized for the worker who has just started to work on a machine. Specialization is recognized for the workers who work for the first time on a new type of wire on the machine or change the working position.

All of the listed categories of approved costs, i.e. wasted time as well as the part of the working time up to $100 \%$ of the achieved norm, are an area where we can identify waste by the Lean methodology [13].

Table 1 Seven basic types of waste in the Shinwon Company

\begin{tabular}{|c|c|c|}
\hline No. & Type of waste & Waste in Shinwon (if it exists) \\
\hline 1 & Overproduction & Does not exist \\
\hline 2 & Transport & Does not exist \\
\hline 3 & Unnecessary movements & $\begin{array}{l}\text { Workers do not use conveyor belts and transfer the product to } \\
\text { the desired location by themselves; Workers do not demand } \\
\text { material from the shift leader and they take it themselves; } \\
\text { Unnecessary walking out of the time for a break. }\end{array}$ \\
\hline 4 & Waiting & $\begin{array}{c}\text { Waiting for the repair of machines; Calibration of machines; } \\
\text { Waiting because of the technological process; Waiting for } \\
\text { delivery. }\end{array}$ \\
\hline 5 & Processing & Does not exist \\
\hline 6 & Inventory & Does not exist \\
\hline 7 & Defects & $\begin{array}{l}\text { Defects during the production; Defects discovered during the } \\
\text { product use by customer. }\end{array}$ \\
\hline
\end{tabular}




\section{5S AUDIT IN THE SHINWON COMPANY}

The Shinwon Company has been implementing the 5S method since its establishment, and is still working on improving it. Each month, quality control managers check the application of this method and whether some aspects should be improved (Fig. 2).

\begin{tabular}{|c|c|c|c|c|c|}
\hline \multicolumn{3}{|c|}{ Audit proces report - $5 \mathrm{~S}$ audit } & & \multicolumn{2}{|c|}{ SHINWON } \\
\hline \multicolumn{6}{|c|}{ Evaluation: 90 points (B grade) } \\
\hline \multicolumn{6}{|c|}{ Date: 20.02 .2015} \\
\hline \multicolumn{6}{|c|}{ Auditors: B. Radovic } \\
\hline \multicolumn{6}{|c|}{ O Evaluation by phase } \\
\hline Sort & Set in order & Shine & Standardize & Sustain & Total (100) \\
\hline 15.5 & 19.5 & 18 & 18 & 19 & 90 \\
\hline \multicolumn{6}{|l|}{ O Criterion } \\
\hline Class & A class & B class & C class & D class & E class \\
\hline Score & 95 points or more & $94.5 \div 85$ points & $84.5 \div 75$ points & $74.5 \div 65$ points & 64.5 points or less \\
\hline \multicolumn{6}{|l|}{ O Checklist } \\
\hline Division & \multicolumn{5}{|c|}{ Results and improvements } \\
\hline Material & \multicolumn{5}{|c|}{$8 \mathrm{~mm}$ copper rod is not placed on proper place and it's not marked } \\
\hline Maintenance & \multicolumn{5}{|c|}{$5 \mathrm{~S}$ rule is broken in maintenance room, there are unnecessary tools and items on work place, work place is not sort } \\
\hline Production & \multicolumn{5}{|c|}{$5 \mathrm{~S}$ rule is broken on drawing machine work place, rubber gloves were found on ink cabinet } \\
\hline Production & \multicolumn{5}{|c|}{ Yellow floor lines are not cleaned well on work position extruder } \\
\hline
\end{tabular}

Fig. 2 Results of internal 5S checking for the month of February

Every question from the checklists was evaluated on a scale from A to E, where:

- A - Outstanding results,

- B - Above average results,

- C - Minimum acceptable level,

- D - Minimum efforts,

- E - Without invested effort.

\section{PARETO ANALYSIS}

The Pareto diagram [14] for the process of production of insulated copper wire is made on the basis of waste (list of 7 basic types of waste), which are analyzed in section 3 of this paper. Waste is monitored on a monthly basis, and includes the categories of interruptions in the work process that are not workers' fault as well as defects and waiting because of machine failure. These are the categories which require improvement in order to increase the efficiency and effectiveness of the production process. The Pareto diagram visually shows which production process is the most commonly interrupted, or which process is the most critical (Fig. 3). 
The interruptions data in operation monitored on a monthly basis are given in minutes for each process for February 2015. The Pareto chart shows that the process in which most interruptions occur is that of isolating copper wire. The reason for this lies in the frequent changes in colors and sizes of the produced wire, and this is the process where it is necessary to implement effective solutions.

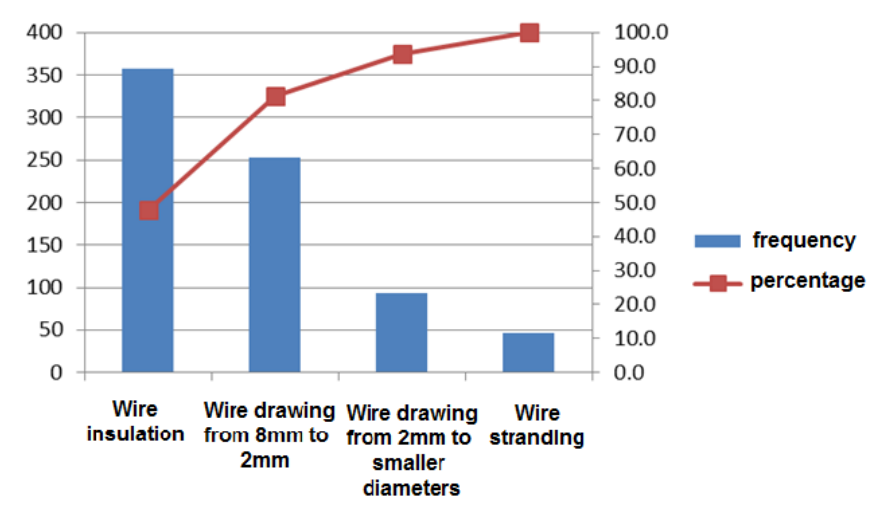

Fig. 3 Pareto diagram of the process in which the waste occurs in the form of breaks

\section{STATISTICAL PROCESS CONTROL}

The methods used in the Shinwon Company are the scatter diagram and process capability indices. The results of measurements based on samples are input by the quality control manager into a control table which is then copied to the internal software for assessing the abilities and performance of the process, which further results in scatter diagrams and abilities indices and performance.

Special emphasis is on the coefficient of potential processes $(\mathrm{Cp})$ and process capability index ( $\mathrm{Cpk}$ ), which measure how much the production process in the Shinwon Company is close to the control limits that are set out in the standards and guidelines for sub-processes. The higher the values of these coefficients the more stable and better process we have.

Table 2 Measurement results for the process of the 0.3 wire insulation

\begin{tabular}{lccc}
\hline Standard & \multicolumn{1}{c}{ Spec } & Analysis & Evaluation \\
\hline $7 / 0.26$ & lower limit: $1.30 \mathrm{~mm}$ & No of samples: 679 & Very stable process \\
$(0.3 \mathrm{SQ})$ & upper limit: $1.50 \mathrm{~mm}$ & $\mathrm{Cp}=4.85$ & \\
& & $\mathrm{CpK}=4.80$ & \\
& & $\mathrm{Pp}=4.57$ & \\
& & $\mathrm{PpK}=4.53$ & \\
& & Sigma level 14.4 & \\
\hline
\end{tabular}




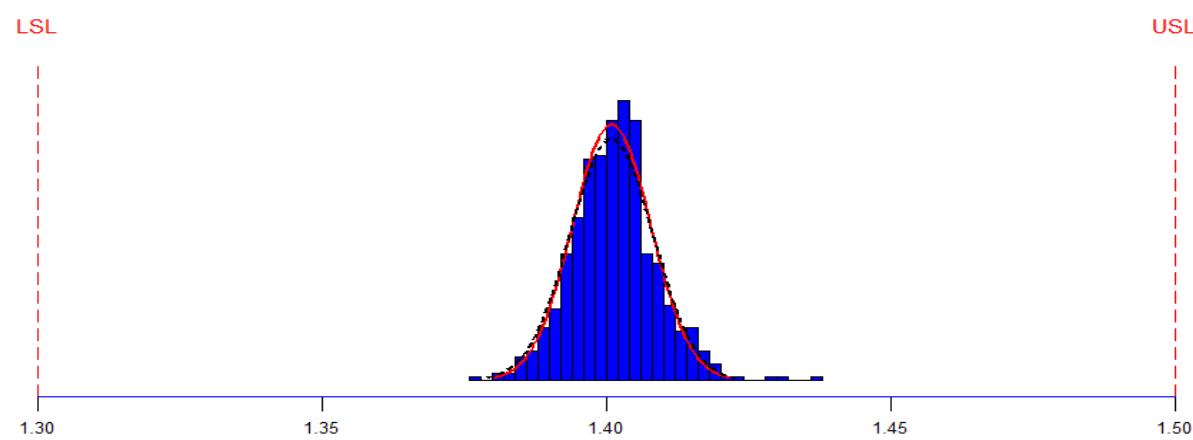

Fig. 4 Graph of stability for the process of insulating the 0.3 wire

The final process, the process of insulating copper wire is stable, capable and accurate, which can be seen from the scatter diagram (Fig. 4) as well as from Cp, Cpk, Pp and Ppk coefficients (Table 2).

\section{ISHIKAWA DIAGRAM}

Based on the previously defined waste appearing in the production process in the Shinwon Company, a cause-effect diagram for the downtime category is created (Fig. 5).

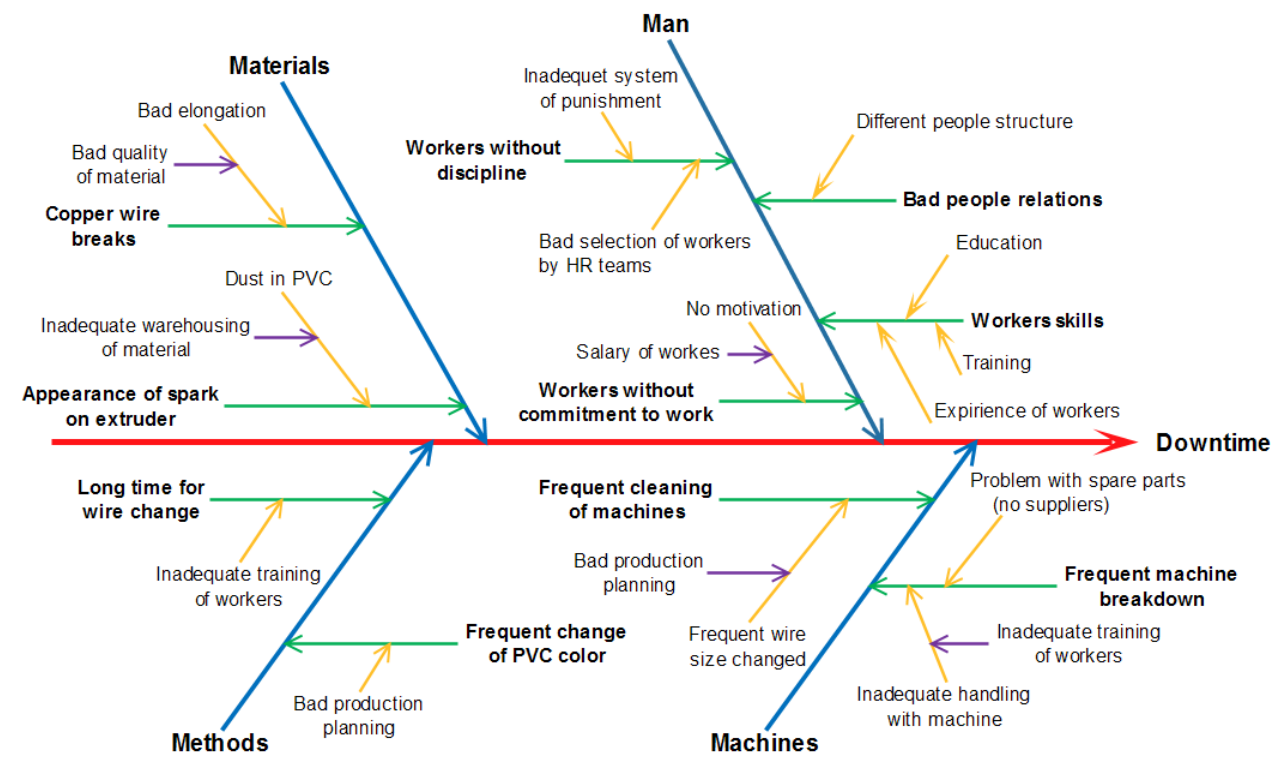

Fig. 5 Ishikawa diagram for the category of interruptions in the working process 
The analysis was performed by the $4 \mathrm{M}$ method where the following main categories are identified: material, people, methods, machines [15]. Through further analysis of these categories and by parsing each of them into increasingly smaller causes, we can conclude that the main problem is the human factor and human errors (inadequate storage of PVC, lack of motivation, different structure of workers, training of workers, poor production planning, etc.).

\section{RESULTS AND DISCUSSION}

Based on the given results of the analysis, we can conclude that the greatest opportunity for improving the production process lies in reducing downtime and avoiding defects.

Improving the process can be achieved by applying the system of incentive payments of salaries based on group and individual performance, adequate and continuous staff training, as well as improving working conditions, because the human factor, or the problem with the employee, arises as the underlying cause problem in production. Workers' skills (poor working experience, training, education) can be improved by a better selection of personnel by the human resource department, as well as better training of the existing employees. The problems of engagement in the workplace and lack of motivation can be eliminated by introducing special incentives for commitment and dedication. The poor interpersonal relationships and non-collegiality can be influenced by the company by organizing joint nonoperating activities, as sports days, excursions, etc., which strengthen the team spirit of employees. Based on the Ishikawa diagram, it can be suggested that the process improvement can be achieved by improving the work schedules, improving the material control in production and increased supplier control. It is noteworthy that the production process in the Shinwon Company represents a viable and stable process in spite of the deficiencies found. The company constantly examines, enhances and improves its process, which is very important in today's market conditions. The focus of the company is the customer, who demands a cheaper product, on time and with better quality, which imposes a constant need to improve the process.

\section{CONCLUSION}

Today's unpredictable and highly competitive business conditions have added significant innovations and imposed a new business philosophy, where the customer is the focus of the business. In these conditions, the Lean Six Sigma philosophy because of its being quick, innovate, cheap and flexible, represents the success of each company [16]. Identifying and eliminating unnecessary and wasteful activities in the business process, concentrating solely on the customer and continuously improving the production process can lead to achieving the maximum quality. Since turbulent business conditions drastically shorten the life of a product, the Lean Six Sigma methods and techniques allow the company to rapidly improve and adapt its performance in accordance with the existing demands. 


\section{REFERENCES}

1. George, M., 2002, Lean Six Sigma: Combining Six Sigma quality with Lean speed, first edition, McGrawHill, New York.

2. Holweg, M., 2007, The genealogy of lean production, Journal of Operations Management, 25(2), pp. 420-437.

3. Bhamu, J., Sangwan, S.K., 2014, Lean manufacturing: literature review and research issues, International Journal of Operation \& Production Management, 34(7), pp. 876-940.

4. Shah, R., Chandrasekaran, A., Linderman, K., 2008, In pursuit of implementation patterns: the context of Lean and Six Sigma, International Journal of Production Research, 46(23), pp. 6679-6699.

5. Assarlind, M., Gremyr, I., Backman, K., 2012, Multi-faceted views on a Lean Six Sigma application, International Journal of Quality \& Reliability Management, 29(1), pp. 21-30.

6. Gupta, V., Acharya, P., Patwardhan, M., 2012, Monitoring quality goals through lean Six-Sigma insure competitiveness, International Journal of Productivity and Performance Management, 61(2), pp. 194-203.

7. Hilton, R.J., Sohal, A., 2012, A conceptual model for the successful deployment of Lean Six Sigma, International Journal of Quality \& Reliability Management, 29(1), pp. 54-70.

8. Timans, W., Antony, J., Ahaus, K., Solingen, R., 2012, Implementation of Lean Six Sigma in small- and medium-sized manufacturing enterprises in the Netherlands, Journal of the Operational Research Society, 63, pp. 339-353.

9. Zhang, Y., Gregory M., Neely A., 2016, Global engineering services: Shedding light on network capabilities, Journal of Operations Management, 42-43, pp. 80-94.

10. Habidin, N.F., Yusof, S. M., 2012, Relationship Between Lean Six Sigma, Environmental Management Systems, and Organizational Performance in the Malaysian Automotive Industry, International Journal of Automotive Technology, 13(7), pp. 1119-1125.

11. Marksberry, P., Badurdeen, F., Maginnis, M.A., 2010, An investigation of Toyota's social-technical systems in production leveling, Journal of Manufacturing Technology Management, 22(5), pp. 604-620.

12. Ohno, T., 1988, Toyota Productivity System, Productivity Press.

13. Womack, J., Jones, D., 2003, Lean thinking, Simon \& Schuster Inc, New York.

14. Grosfiled-Nir, A., Ronen, B. Kozlovsky, N., 2007, The Pareto managerial principle: When does it apply?, International Journal of Production Research, 45(10), pp. 2317-2325.

15. Ishikawa, K., 1982, Guide to Quality Control, Asian Productivity Organization, Tokyo.

16. Womack, J., Jones, D., Roos, D., 1990, The machine that changed the World: The story of Lean Production, Rawson and Associates, New York. 